\title{
Flavonoids in Ginkgo biloba fallen leaves induce apoptosis through modulation of p53 activation in melanoma cells
}

\author{
HYE-JUNG PARK and MOON-MOO KIM \\ Department of Chemistry, Dong-Eui University, Busan 614-714, Republic of Korea
}

Received July 15, 2014; Accepted October 21, 2014

DOI: 10.3892/or.2014.3602

\begin{abstract}
The aim of the present study was to examine the apoptotic effect of flavonoids in methanol extracts of Ginkgo biloba fallen leaves (MEGFL) on melanoma cells. Ginkgo biloba is a deciduous castle chaplain and its leaves include various types of flavonoids such as flavonol- $O$-glycosides. Ginkgo biloba is known to have therapeutic properties against a number of diseases such as cerebrovascular diseases, blood circulation disease and hypertension. In the present study MEGFL exhibited a higher cytotoxic effect on melanoma cells than Ginkgo biloba leaves (MEGL). It was also found that MEGFL induced apoptotic cell death which was characterized by DNA fragmentation. During the cell death process following treatment with MEGFL, the expression of a variety of death-associated proteins including $\mathrm{p} 53$, caspase-3, caspase-9, cytochrome $c$ and Bax were analyzed in the cytosol of melanoma cells. MEGFL significantly increased the expression levels of caspase-3, caspase-9 and p53 in a dose-dependent manner. Our results indicate that MEGFL induced apoptotic cell death by increasing the expression of cell death-associated proteins in melanoma cells.
\end{abstract}

\section{Introduction}

Although medical technology has experienced great advances, to date cancer still remains an unsolved major health issue. In recent years, the most promising chemotherapy for the treatment of cancer is known to induce apoptosis. Cell mutations and their unrepaired DNA damage not only adversely affect the surrounding normal cells but also initiate diseases such as cancer (1). For escaping these risks, cells operate self death systems such as apoptosis. Cancer cells have the ability to evade signal stimulation inducing apoptosis. Therefore, apoptosis induction may represent a new therapeutic strategy for the treatment of cancer. Apoptosis is proceeded by various death-associated proteins such as the caspase family, the

Correspondence to: Professor Moon-Moo Kim, Department of Chemistry, Dong-Eui University, Busan 614-714, Republic of Korea E-mail:mmkim@deu.ac.kr

Key words: Ginkgo biloba fallen leaves, flavonoids, B16F1, apoptosis, p53, caspase
Bcl-2 family, mitogen-activate protein kinase (MAPK) and tumor-suppressor genes such as p53. The caspase family is divided into initiator caspases and effector caspases (2). When killer T cells detect damaged cells, procaspase- 8 is activated by CFasL/D95L a death ligand that binds to the surface of death receptors such as Fas, tumor necrosis factor receptor-1 (TNFR-1) and TNFR-2 (3). Caspase-8, an initiator caspase, induces the break-down of proteins, the actin cytoskeleton and lamin protein, a protein of the nuclear membrane, by activation of caspase-3 and other effector caspases, and then causes cell death through DNA fragmentation $(2,4,5)$. In contrast, the mitochondrial apoptotic pathway is initiated by the release of cytochrome $c$ from mitochondria into the cytosol by external death stimulation (6). The apoptosome formed by binding the cytochrome $c$ to the complex of apoptotic protease activation factor-1 (Apaf-1) and procaspase-9 activates capase-9 and caspase-3, then finally resulting in apoptosis. This mitochondrial pathway is controlled by the Bcl-family (7) that includes both proapoptotic factors and antiapoptotic factors. In normal cells, the antiapoptotic factors inhibit the release of cytochrome $c$ from mitochondria. However, once external death signals are transmitted to them, they cause the release of cytochrome $c$. When DNA damage is not successfully repaired, it induces apoptosis through activation of Bax, a proapoptosis factor as previously described (2). Hypoxia and a malnutrition condition strongly induce apoptosis as cancer cells proliferate at a rapid rate. Moreover, cancer cells evade apoptosis through downregulation of proapoptotic factors and upregulation of antiapoptotic factors. Thus, apoptosis is a valuable target for the development of anticancer drug since apoptotic cells form apoptotic bodies that are removed by macrophages proceeding inflammation.

Ginkgo biloba is deciduous castle chaplain, and numerous studies have reported the physiological effects of Ginkgo biloba leaves. The major classes of constituents in Ginkgo biloba leaves include flavonoids, diterpenes, sesquiterpenes, polyphenol, organic acid, and polycaccharide (8). Among these, the major components in Ginkgo biloba are flavonoids such as quercetin, kaempferol, rutin and robinin. In particular, most of the physiological effects of Ginkgo biloba are the result of flavonoids and terpenes. The extract of Ginkgo biloba leaves has been used as a therapeutic agent for ischemic stroke, ischemic heart disease and atherosclerosis, and has been reported to have antioxidant, memory and blood circulation effects (9). Particularly, the extract of Ginkgo biloba leaves was found to 
inhibit amyloid- $\beta$ fibril formation and activate caspase- 3 and was demonstrated to have an Alzheimer's disease protective effect through repressing the apoptosis of neuronal cells (10). In contrast, other studies have found that kaempferol contained in extracts of Ginkgo biloba leaves induced the apoptosis of pancreatic cancer cells (11). However, the physiological effects of Ginkgo biloba fallen leaves has not been investigated to date. Therefore, the aim of this study was to investigate the potential of Ginkgo biloba fallen leaves as a cancer therapeutic agent by studying the inductive effect of apoptosis on a murine melanoma cell line.

\section{Materials and methods}

Materials. Dulbecco's modified Eagle's medium (DMEM), trypsin-EDTA, penicillin/streptomycin/amphotericin $(10,000 \mathrm{U} / \mathrm{ml}, 10,000 \mathrm{~g} / \mathrm{ml}$ and 2,500 g/ml, respectively) and fetal bovine serum (FBS) were obtained from Gibco-BRL, Life Technologies (Grand Island, NY, USA). B16F1 (ATCC no. CRL-6323) cells were purchased from the American Type Culture Collection (ATCC). MTT reagent, agarose, and other materials were purchased from Sigma Chemical Co. (St. Louis, MO, USA).

Extract preparation. For producing the methanol extracts of Ginkgo biloba fallen leaves, air-dried Ginkgo biloba leaves (MEGL) and fallen leaves (MEGFL) underwent extraction with $95 \%$ methanol, respectively. The solvent was evaporated in vacuo to yield $50.0 \mathrm{~g}$ of MEGFL as a dark brown solid material. MEGFL ( $1 \mathrm{~g}$ ) was suspended in $10 \mathrm{ml}$ of methanol, and was subjected to membrane $(0.45 \mu \mathrm{m})$ filtration. The extracts were dissolved in DMSO for this study.

Spectrophotometric determination of flavonoid. The total flavonoid content in the MEGFL was determined according to a modified version of the Folin-Ciocalteu method (12) using phloroglucinol as the standard. Samples were diluted taking into account the measurable range of the spectrophotometer (a $0.005-\mathrm{ml}$ aliquot of extract of soluble phenolics was mixed with $0.495 \mathrm{ml}$ water). A $0.1-\mathrm{ml}$ aliquot of the diluted sample was mixed in a test tube with $1.0 \mathrm{ml}$ of $1 \mathrm{~N}$ Folin-Ciocalteu reagent. The mixture was allowed to stand for $3 \mathrm{~min}$ following addition of $2.0 \mathrm{ml}$ of $20 \% \mathrm{Na}_{2} \mathrm{CO}_{3}$. The samples were incubated in the dark at room temperature for $45 \mathrm{~min}$ and centrifuged at $1,600 \mathrm{x} g$ for $8 \mathrm{~min}$. The optical density (OD) of the supernatant was measured at $730 \mathrm{~nm}$ using a GENios ${ }^{\circledR}$ microplate reader (Tecan Austria $\mathrm{GmbH}$, Austria). The total flavonoid content was calculated using a standard plotted graph and was expressed as a percentage.

Cell line and culture. The cell lines were separately grown as monolayers in $5 \% \mathrm{CO}_{2}$ and at $37^{\circ} \mathrm{C}$ in a humidified atmosphere using appropriate media supplemented with 5\% FBS, $2 \mathrm{mM}$ glutamine and $100 \mathrm{~g} / \mathrm{ml}$ penicillin-streptomycin. DMEM was used as the culture medium for the B16F1 cell line. Cells were passaged 3 times a week by treatment with trypsin-EDTA.

MTT assay. Cytotoxic levels of MEGFL were measured using 3-(4,5-dimethylthiazol-2-yl)-2,5-diphenyltetrazolium bromide (MTT) method. The B16F1 cell line was grown in 96-well plates at a density of $5 \times 10^{3}$ cells/well. After $24 \mathrm{~h}$, the cells were washed with fresh medium and were treated with MEGFL at $1,2,4,6,8,10,50$ and $100 \mu \mathrm{g} / \mathrm{ml}$. After $48 \mathrm{~h}$ of incubation, the cells were rewashed, and $20 \mu \mathrm{l}$ of MTT $(5 \mathrm{mg} / \mathrm{ml})$ was added and incubation was carried out for $4 \mathrm{~h}$. Finally, DMSO $(150 \mu \mathrm{l})$ was added to solubilize the formazan salt formed, and the amount of formazan salt was determined by measuring the OD at $540 \mathrm{~nm}$ using a GENios ${ }^{\circledR}$ microplate reader (Tecan Austria $\mathrm{GmbH}$ ). The relative cell viability was determined by the amount of MTT converted into formazan salt. The viability of the cells was quantified as a percentage compared to the control (OD of treated cells/OD of blank $x$ 100) and the dose response curves were developed. The data are expressed as the means from at least three independent experiments, and $\mathrm{P}<0.05$ was considered to indicate a statistically significant result.

Reducing power. The reducing power of MEGFL was determined using a method described previously (13). The absorbance of this mixture was measured at $700 \mathrm{~nm}$. The level of reducing power was calculated by the absorbance and expressed as a percentage: Reducing power $=(\mathrm{OD}$ of MEGFL/ OD of blank) x 100 .

DNA oxidation. Genomic DNA was extracted from the B16F1 cells using a standard phenol/proteinase $\mathrm{K}$ procedure. The purity of genomic DNA was spectrophotometrically determined at 260/280 $\mathrm{nm}$. DNA oxidation mediated by the Fenton reaction was determined by a method described elsewhere (14). One hundred microliters of the DNA reaction mixture was prepared by adding pre-determined concentrations of the test sample (or the same volume of $10 \%$ FBS/DMEM with Fenton reaction as the control group), $200 \mu \mathrm{M}$ final concentration of $\mathrm{FeSO}_{4}, 2 \mathrm{mM}$ final concentration of $\mathrm{H}_{2} \mathrm{O}_{2}$ and $50 \mu \mathrm{g} /$ $\mathrm{ml}$ final concentration of genomic DNA in the same order. Then the mixture was incubated at room temperature for $30 \mathrm{~min}$, and the reaction was terminated by adding a final concentration of $10 \mathrm{mM}$ of EDTA. An aliquot $(20 \mu \mathrm{l})$ of the reaction mixture containing $\sim 5 \mu \mathrm{g}$ of DNA was electrophoresed on $1 \%$ agarose gel for $30 \mathrm{~min}$ at $100 \mathrm{~V}$. The gels were then stained with $1 \mathrm{mg} / \mathrm{ml}$ ethidium bromide and visualized by UV light using AlphaEase ${ }^{\circledR}$ gel image analysis software (Alpha Innotech, San Leandro, CA, USA). The protective effect of MEGFL was quantified as a percentage compared to the blank group (density of the genomic DNA band treated with MEGFL/density of the intact genomic DNA band x 100).

DNA ladder assay. For the DNA fragmentation analysis, the cells were treated with different concentrations of MEGFL. DNA was isolated from the cells, as follows. Cells were washed twice in phosphate-buffered saline (PBS), resuspended in lysis buffer (10 mM EDTA, 20 mM Tris, pH 8.0,0.5\% Triton X-100) and incubated at $50^{\circ} \mathrm{C}$ for $1 \mathrm{~h}$. RNase A was added to a final concentration of $0.5 \mathrm{mg} / \mathrm{ml}$, and incubation was continued at $50^{\circ} \mathrm{C}$ for $1 \mathrm{~h}$. Samples were then extracted with phenolchroloform-isoamyl alchohol (25:24:1). High molecular weight DNA was then pelleted at $13,000 \times \mathrm{g}$ for $10 \mathrm{~min}$, and the low molecular weight DNA in the supernatant was removed and precipitated overnight in two volumes of ice-cold ethanol at $-70^{\circ} \mathrm{C}$. 

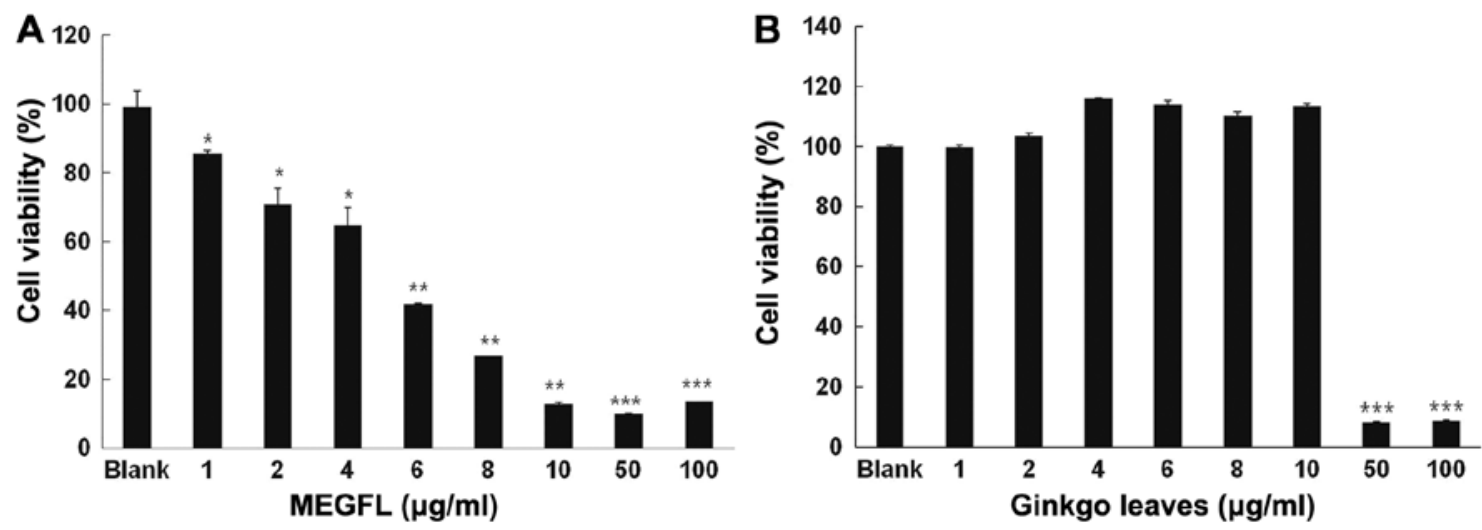

Figure 1. Effect of methanol extracts of Ginkgo biloba fallen leaves (MEGFL) on the viability of B16F1 cells. Cells were treated with (A) MEGFL and (B) MEGL at the indicated concentrations, and cell viability was determined by the MTT assay after $24 \mathrm{~h}$. Data are expressed as the mean values \pm SD from three independent experiments. Level of significance was identified statistically $\left({ }^{*} \mathrm{P}<0.05,{ }^{* * *} \mathrm{P}<0.01\right.$ and $\left.{ }^{* * * *} \mathrm{P}<0.001\right)$ using the Student's t-test.

Analyses of protein expression using western blot analysis. Western blotting was performed according to standard procedures. Cells treated with different concentrations of MEGFL were lysed with RIPA lysis buffer (Sigma Chemical Co.). Cell lysates were resolved on a $4-20 \%$ Novex $^{\circledR}$ gradient gel (Invitrogen, USA), electrotransferred onto a nitrocellulose membrane and blocked with $10 \%$ skim milk. The primary antibodies including p53, p-p53, Ac-p53, p-p21, caspase-3, caspase-9, Bcl-2, cytochrome $c, \beta$-actin and their secondary antibodies (Santa Cruz Biotechnology, Inc., Santa Cruz, CA, USA) were used to detect the respective proteins using a chemiluminescent ECL assay kit (Amersham Pharmacia Biotech, Piscataway, NJ, USA) according to the manufacturer's instructions. Protein bands were visualized using AlphaEase ${ }^{\circledR}$ gel image analysis software (Alpha Innotech).

Statistics. Data were analyzed using the Student's t-test for paired data (comparison of the control group and MEGFL). Data are expressed as means \pm SD from three independent experiments. $\mathrm{P}<0.05, \mathrm{P}<0.01$ and $\mathrm{P}<0.001$ are indicative of statistically significant results, and are indicated in the figures and legends.

\section{Results}

Flavonoid contents in MEGL and MEGFL. Flavonoids are produced entirely by polymerization of phloroglucinol, which is a product of the acetate-malonate pathway, also known as the polyketide pathway. Following extraction with methanol, harvest yields of MEGL and MEFGL were 13.40 and 26.22\%, respectively, from starting material at dry weight basis. MEGFL consisted of $5.50 \pm 0.21 \%$ of flavonoids at dry weight basis. In contrast, the methanol extract of Ginkgo biloba leaves consisted of $1.87 \pm 0.17 \%$ of flavonoids at dry weight basis.

Effect of MEGFL on cell viability. To investigate the cytotoxic effect of MEGFL, MTT assay was carried out in the B16F1 cell line. The cells were treated with MEGFL at the indicated doses for $48 \mathrm{~h}$. MEGFL exhibited a cytotoxic effect in a dosedependent manner in the B16F1 cell line (Fig. 1A). MEGFL at $100 \mu \mathrm{g} / \mathrm{ml}$ inhibited cell viability by $80 \%(\mathrm{P}<0.001)$. However, MEGL did not exhibit any cytotoxicity at a concentration

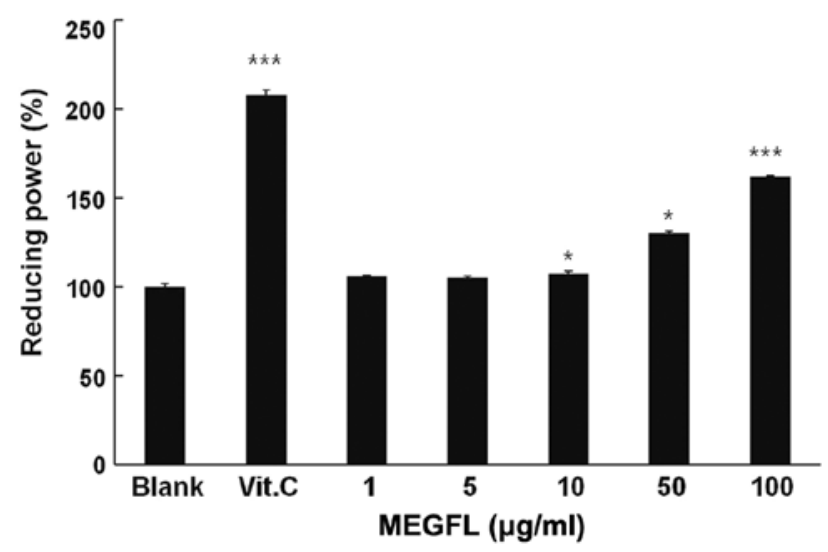

Figure 2. Effect of methanol extracts of Ginkgo biloba fallen leaves (MEGFL) on reducing power. The scavenging activity of MEGFL on reducing power was evaluated in the presence of MEGFL. After MEGFL at the indicated concentration was reacted with each radical, the optical density of each reaction mixture was measured at a specific wavelength with a spectrophotometer. Data are expressed as mean values \pm SD from three independent experiments. Level of significance was identified statistically ( $\mathrm{P}<0.05$ and $\left.{ }^{* * *} \mathrm{P}<0.001\right)$ using the Student's t-test.

$<10 \mu \mathrm{g} / \mathrm{ml}$. It was found that MEGL at a concentration $>50 \mu \mathrm{g} /$ $\mathrm{ml}$ showed cytotoxicity in B16F1 cells (Fig. 1B).

Reducing power of MEGFL. The reducing ability of a compound generally depends on the presence of a reducing agent which exhibits antioxidative potential by breaking the free radical chain, donating a hydrogen atom. Vitamin $\mathrm{C}$ at $100 \mu \mathrm{g} / \mathrm{ml}$ significantly displayed reducing power compared with the blank group $(\mathrm{P}<0.001)$ (Fig. 2). MEGFL significantly showed reducing power in a dose-dependent manner. In particular, it was observed that MEGFL increased the reducing power by $60 \%$ compared with the blank group without MEGFL treatment.

Inhibition of radical-mediated DNA oxidative damage by $M E G F L$. In a subsequent experiment, genomic DNA was isolated from $\mathrm{B} 16 \mathrm{~F} 1$ cells to study the protective effect of MEGFL against DNA oxidative damage induced by hydroxyl radical. The genomic DNA of the control group was completely degraded by the hydroxyl radical produced by the 


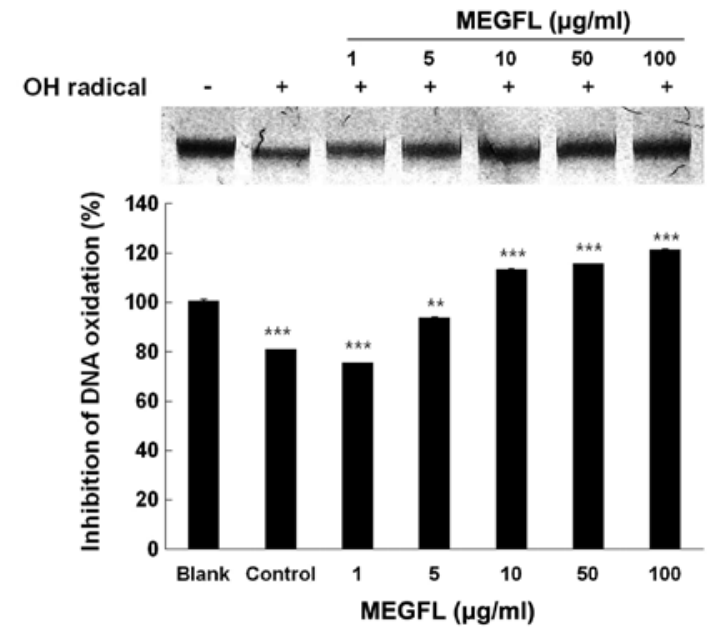

Figure 3. Protective effect of methanol extracts of Ginkgo biloba fallen leaves (MEGFL) on DNA oxidative damage induced by hydroxyl radical. Genomic DNA purified from B16F1 cells was pretreated with MEGFL for $1 \mathrm{~h}$ and exposed to ${ }^{\circ} \mathrm{OH}$ using the Fenton reaction. After $30 \mathrm{~min}$, the reaction mixture containing $\sim 1 \mu \mathrm{g}$ of DNA was electrophoresed on a $1 \%$ agarose gel for $30 \mathrm{~min}$ at $100 \mathrm{~V}$ and visualized by UV light after staining with $1 \mathrm{mg} / \mathrm{ml}$ ethidium bromide. Data are expressed as the mean values \pm SD from three independent experiments. Level of significance as identified statistically $\left({ }^{* *} \mathrm{P}<0.01\right.$ and $\left.^{* * * *} \mathrm{P}<0.001\right)$ using the Student's t-test.

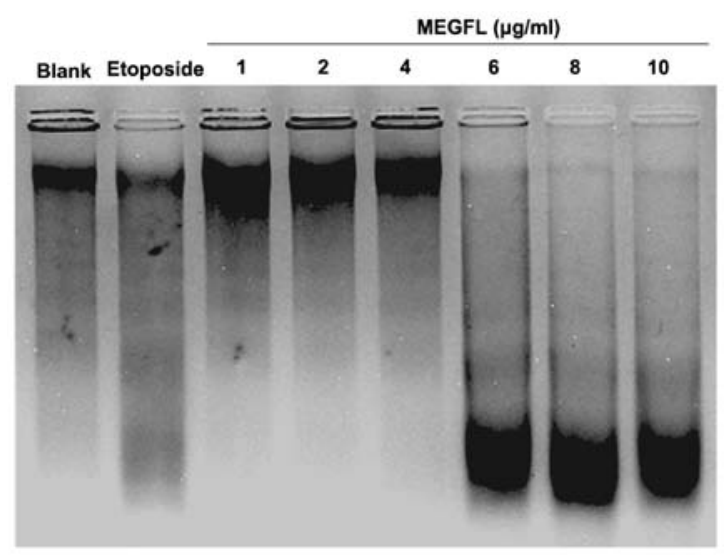

Figure 4.Effect of methanol extracts of Ginkgo biloba fallen leaves (MEGFL) on DNA fragmentation by MEGFL. Cells were treated with various concentrations of MEGFL for $24 \mathrm{~h}$. The genomic DNA was extracted, separated on $2 \%$ agarose gel electrophoresis and visualized under UV light after staining with EtBr.

Fenton reaction, compared with the blank group without the Fenton reaction (Fig. 3). Treatment with MEGFL at $10 \mu \mathrm{g} / \mathrm{ml}$ or more significantly inhibited the oxidative damage of DNA $(\mathrm{P}<0.001)$. The DNA damage was inhibited by $80 \%$ in the presence of MEGFL at $10 \mu \mathrm{g} / \mathrm{ml}$, compared with the control group treated with the same volume of 5\% FBS/DMEM/instead of the test sample with the Fenton reaction. However, it was found that MEGFL at $1 \mu \mathrm{g} / \mathrm{ml}$ could not clearly protect the oxidative damage of DNA by the hydroxyl radical.

Effect of MEGFL on DNA fragmentation. To investigate the effect of MEGFL on DNA fragmentation, DNA of B16F1 cells treated with MEGFL was observed using the technique of DNA electrophoresis. Etoposide at $100 \mu \mathrm{M}$ was used as a positive control for DNA fragmentation. DNA of cells treated with

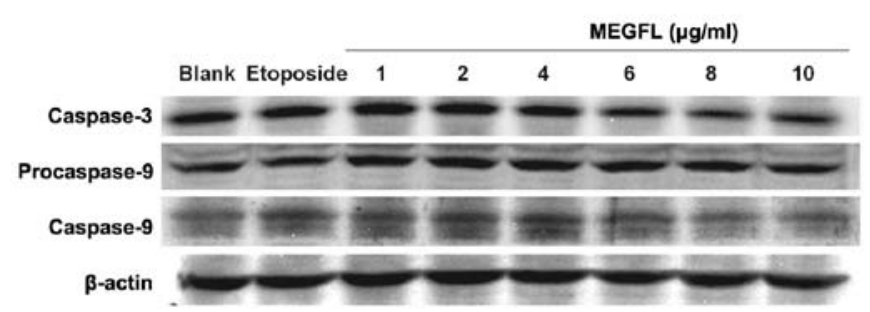

Figure 5. Effect of methanol extracts of Ginkgo biloba fallen leaves (MEGFL) on the protein expression levels of caspase- 3 and caspase- 9 in the B16F1 cell line. The cells were treated with MEGFL at concentrations of 1, 2, 4, 6, 8 and $10 \mu \mathrm{g} / \mathrm{ml}$. Western blot analyses of cell lysates were performed using antibodies as indicated. The expression level of $\beta$-actin was used as a control for normalization of the target proteins.

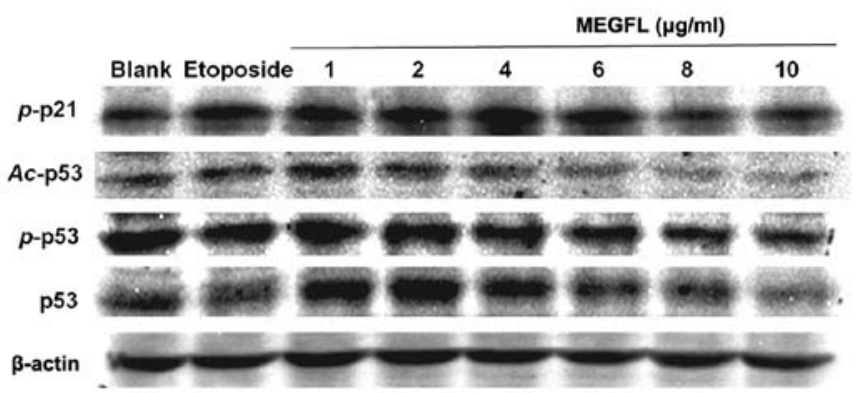

Figure 6. Effect of methanol extracts of Ginkgo biloba fallen leaves (MEGFL) on the protein expression levels of p53, phosphorylated (p)-p53, acetylated (Ac)-p53 and p-p21 in the B16F1 cell line. The cells were treated with MEGFL at concentrations of $1,2,4,6,8$ and $10 \mu \mathrm{g} / \mathrm{ml}$. Western blot analyses of cell lysates were performed using antibodies as indicated. The expression level of $\beta$-actin was used as a control for normalization of the target proteins.

etoposide was cleaved compared to the blank group without any stimulation (Fig. 4). Furthermore, MEGFL had an inductive effect on DNA fragmentation in a dose-dependent manner and showed apoptosis at a concentration of MEGFL $>6 \mu \mathrm{g} / \mathrm{ml}$.

Effect of MEGFL on the protein expression levels of caspase-3 and caspase-9. During the apoptosis process, caspases play a key role in protein cleavage. To investigate the effect of MEGFL on the protein expression levels of caspase-3 and caspase-9, western blot analysis was carried out in $\mathrm{B} 16 \mathrm{~F} 1$ cells. Etoposide at $100 \mu \mathrm{M}$ was used as a positive control. The protein expression levels of caspase- 3 and caspase- 9 were significantly increased in the presence of etoposide and MEGFL in the range from 1 to $4 \mu \mathrm{g} / \mathrm{ml}$ compared with the blank group (Fig. 5). However, MEGFL decreased the protein expression levels of caspase- 3 and caspase- 9 in the presence of MEGFL at $6 \mu \mathrm{g} / \mathrm{ml}$.

Effect of MEGFL on the protein expression levels of p53, phosphorylated p53, acetylated p53 and phosphorylated p21. When DNA damage occurs, p53 is activated to repair DNA or to induce apoptosis. The activation of p53 is controlled by $\mathrm{p} 53$ phosphorylation and acetylation. In addition, p53, a transcription factor, binds to the promoter of p21. p21 is closely associated with cell cycle arrest. As shown in Fig. 6, consistent with the results shown in Fig. 5 the protein expression levels of p53, 


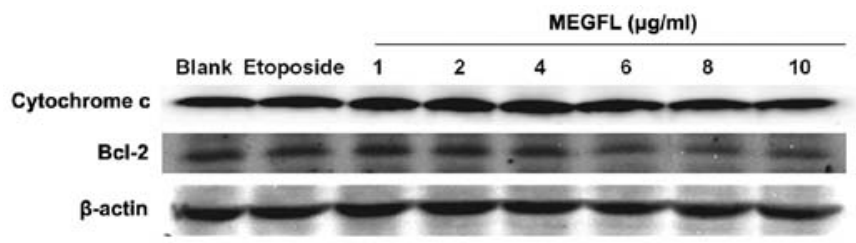

Figure 7. Effect of methanol extracts of Ginkgo biloba fallen leaves (MEGFL) on the protein expression levels of cytochrome $c$ and Bcl-2 in the B16F1 cell line. The cells were treated with MEGFL at concentrations of 1, 2, 4, 6, 8 and $10 \mu \mathrm{g} / \mathrm{ml}$. Western blot analyses of cell lysates were performed using antibodies as indicated. The expression level of $\beta$-actin was used as a control for normalization of the target proteins.

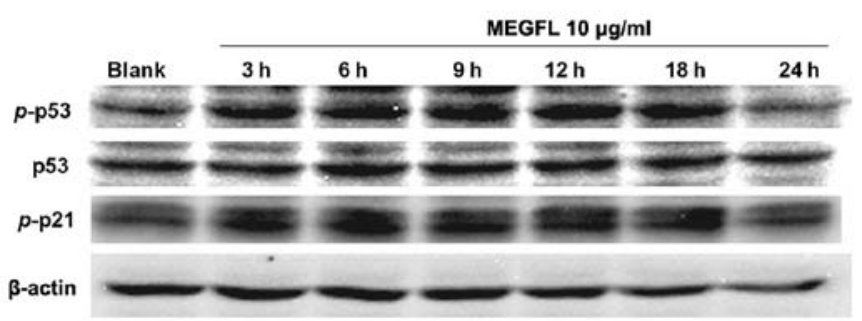

Figure 8. Effect of methanol extracts of Ginkgo biloba fallen leaves (MEGFL) on the protein expression levels of p53, phosphorylated (p)-p53 and p-p21 with time in the B16F1 cell line. The cells were exposed to MEGFL at $10 \mu \mathrm{g} /$ $\mathrm{ml}$ for various time periods. Western blot analyses of cell lysates were performed using antibodies as indicated. The expression level of $\beta$-actin was used as a control for normalization of the target proteins.

phosphorylated p53 (p-p53 and Ser15), acetylated p53 (Ac-p53 and Lys373-382) and phosphorylated p21 (p-p21 and Ser146) were increased in the presence of etoposide and MEGFL at a range from 1 to $4 \mu \mathrm{g} / \mathrm{ml}$. MEGFL treatment at concentrations $>6 \mu \mathrm{g} / \mathrm{ml}$ caused a reduction in the protein expression levels. These results suggest that the altered expression levels of p53 and p-p21 are related to cell death.

Effect of MEGFL on the protein expression levels of cytochrome $c$ and $B c l-2$. During the apoptosis process, the cytochrome $c$ released from mitochondria activates caspase leading to cell death. This mitochondrial pathway is regulated by the Bcl-2 family. It was found that the protein expression levels of cytochrome $c$ and Bcl-2 were not altered in the presence of etoposide and MEGFL when compared with the blank group (Fig. 7). These results indicate that MEGFL does not induce apoptosis through the mitochondrial-dependent pathway.

Effect of MEGFL on the protein expression levels of p53, phosphorylated p53 and phosphorylated p 21 with time. To confirm that these protein expression levels are associated with cell death, cells were treated with MEGFL at $10 \mu \mathrm{g} / \mathrm{ml}$ for increasing treatment times. The protein expression levels of p53, p-p53 and p-p21 were increased at $18 \mathrm{~h}$ (Fig. 8). But their expression levels were reduced at $24 \mathrm{~h}$ due to cell death.

\section{Discussion}

The aim of the present study was to investigate the potential of MEGFL to induce apoptosis through modulation of p53 activation in the B16F1 cell line. Apoptosis, programmed cell death by signal interaction, is not only a necessary process to ensure body shape in ontogeny but also a protective reaction against a detrimental influence on healthy cells surrounding diseased cells when found to be seriously damaged $(15,16)$. In contrary with necrosis, apoptosis dose not release toxic substance out of cells. Therefore, it was suggested that apoptosis can be used as a target with which to treat cancer (17). In the present study, an MTT assay was initially carried out to investigate the effect of MEGFL on induction of apoptosis. Consequently, MEGFL caused cell death of the B16F1 cell line. MEGFL exhibited apoptosis at a much lower concentration when compared with other plant extracts. We carried out various characteristic experiments concerning apoptosis to support that cell death was the result of the apoptosis induced by MEGFL. Apoptosis exhibits DNA laddering through cut linker region between nucleosome as 180-200 base pair length while necrosis causes random DNA cleavage. In order to examine the DNA ladder effect of MEGFL, a DNA ladder assay was performed. Etoposide, a well-known positive control, and MEGFL clearly indicated DNA laddering compared with the blank group without treatment. Especially, MEGFL caused marked DNA laddering at $6 \mu \mathrm{g} / \mathrm{ml}$ or more. This result was associated with the tendency of protein expression related to apoptosis. However, most cells were dead in the presence of MEGFL at $6 \mu \mathrm{g} / \mathrm{ml}$. Apoptosis is initiated by various proteins such as the caspase family and Bcl-2 family $(18,19)$. The caspase family, cystein-dependent aspartate-specific protease, is divided into initiator caspases and effector caspases. During the cell death process, caspase- $8,-9$ and -10 , initiator caspases, transmit apoptotic signals, and caspase- $3,-6$ and -7 , effector caspases, exert the effect to degrade protein $(4,20)$. Our results suggest that MEGFL activated caspase-9 through cleavage of procaspase-9 in the presence of MEGFL. Furthermore, the protein expression level of caspase- 3 was increased in the presence of MEGFL. In general, the apoptosome is a complex formed with Apaf-1 that is activated by cytochrome $c$ released from mitochondria into the cytosol. It subsequently activates caspase-3 leading to apoptosis. Both the expression levels of cytochrome $c$ and Bcl-2, an antiapoptotic factor, were not altered at a nontoxic concentration of MEGFL. p-p21 arrests the cell cycle not only through inhibition of cyclin D/CDK4 and cyclin E/CDK2 complexes in early G1 phase but also inhibiton of cyclin $\mathrm{A} / \mathrm{CDK} 2$ complex prior to the $\mathrm{S}$ phase/G2 phase transition $(2,21)$. MEGFL highly increased the protein expression level of p-p21 (Ser146) at nontoxic concentrations. Therefore, our findings revealed that MEGFL inhibits cell proliferation by disturbing progression of the cell cycle. p53, a transcription factor binding to the promoter of $\mathrm{p} 21$, is a normal short-lived protein that is maintained at low levels, yet p53 is transiently accumulated when serious DNA damage occurs in cells. p53 modulates the cell cycle through induction or inhibition of WAF1, AFN and MDM $(22,23)$. When DNA damages are induced, the cell cycle is arrested and p53 is activated for DNA repair. If DNA repair is not successful, p53 causes apoptosis by induction of Bax (24). Stability and site-specific DNA-binding activity of p53 are associated with phosphorylation and acetylation of p53 (25). The phosphorylation of p53 is caused by protein kinase $\mathrm{C}$ (PKC) at Ser378 and by casein kinase 2 (CK2) at Ser392. The carboxy-terminal region of 
p53, including phosphorylation by CK2 and PKC kinases and truncation of the last 30 residues, modulate the ability of p53 to bind its recognition site through the central sequence-specific DNA-binding domain $(23,26)$. On the other hand, acetylation of p53 is formed by histone acetyl transferases (HATs) such as p300 and PCAF. The p300 acetylates Lys382 in the carboxyterminal region of p53, whereas PCAF acetylates Lys320 in the nuclear localization signal. Acetylations at either site enhance sequence-specific DNA binding site of p21 (27). Our results suggest that MEGFL increased the protein expression level of p53 at nontoxic concentrations. Notably, the expression levels of all proteins were decreased following treatment of MEGFL above a concentration of $6 \mu \mathrm{g} / \mathrm{ml}$. This was caused by cell death. Like the preceding results, MEGFL increased both the protein expression levels of phosphorylate p53 at the $\mathrm{C}$ terminal region (Ser15) and acetylated p53 at the $\mathrm{C}$ terminal region (Lys373-382) at nontoxic concentrations. To support these results, we investigated the protein expression levels of p53, p-p53 and p-p21 with increasing treatment times. While the expression level of p53 was constant at a nontoxic exposure time with MEGFL, up to $18 \mathrm{~h}$, both the expression levels of p-p53, an activated form, and p-p21 were increased. However their expression levels were reduced at $24 \mathrm{~h}$ due to cell death. These results suggest that MEGFL induced activation of p21 through modulation of p53, CDK inhibitor. Furthermore, our findings revealed that MEGFL induced apoptosis by inhibiting cell proliferation as a result of disturbing progression of the cell cycle and increasing the expression levels of caspase-3 and caspase-9. In addition MEGFL has an antioxidant effect through enhancing reducing power and DNA protection. Therefore, this study provides evidence that MEGFL has the potential to cause apoptosis induction, and represents a new therapeutic strategy for the treatment of cancer.

\section{Acknowledgements}

This study was supported by the Basic Science Research Program through the National Research Foundation of Korea (NRF) funded by the Ministry of Science, ICT and Future Planning (no. 2013R1A1A1A05005160).

\section{References}

1. Maynard S, Schurman SH, Harboe C, de Souza-Pinto NC and Bohr VA: Base excision repair of oxidative DNA damage and association with cancer and aging. Carcinogenesis 30: 2-10, 2009.

2. Singhal S, Vachani A, Antin-Ozerkis D, Kaiser LR and Albelda SM: Prognostic implications of cell cycle, apoptosis, and angiogenesis biomarkers in non-small cell lung cancer: a review. Clin Cancer Res 11: 3974-3986, 2005.

3. Aamodt HM, Clifford A, Ellingson CC, Burnett SH, Murray BK and O'Neill KL: Apoptosis through Fas-mediated suicide gene induction in mouse melanoma. AACR 2005: 414, 2005.

4. Mashima T, Naito M and Tsuruo T: Caspase-mediated cleavage of cytoskeletal actin plays a positive role in the process of morphological apoptosis. Oncogene 18: 2423-2430, 1999.

5. Mashima T, Naito M, Noguchi K, Miller DK, Nicholson DW and Tsuruo T: Actin cleavage by CPP-32/apopain during the development of apoptosis. Oncogene 14: 1007-1012, 1997.
6. Caroppi P, Sinibaldi F, Fiorucci L and Santucci R: Apoptosis and human diseases: mitochondrion damage and lethal role of released cytochrome $c$ as proapoptotic protein. Curr Med Chem 16: 4058-4065, 2009.

7. Estaquier J, Vallette F, Vayssiere JL and Mignotte B: The mitochondrial pathways of apoptosis. Adv Exp Med Biol 942: 157-183, 2012.

8. van Beek TA and Montoro P: Chemical analysis and quality control of Ginkgo biloba leaves, extracts, and phytopharmaceuticals. J Chromatogr A 1216: 2002-2032, 2009.

9. Yoshikawa T, Naito Y and Kondo M: Ginkgo biloba leaf extract review of biological actions and clinical applications. Antioxid Redox Signal 1: 469-480, 1999.

10. Luo Y, Smith JV, Paramasivam V, et al: Inhibition of amyloidbeta aggregation and caspase-3 activation by the Ginkgo biloba extract EGb761. Proc Natl Acad Sci USA 99: 12197-12202, 2002.

11. Zhang Y, Chen AY, Li M, Chen C and Yao Q: Ginkgo biloba extract kaempferol inhibits cell proliferation and induces apoptosis in pancreatic cancer cells. J Surg Res 148: 17-23, 2008.

12. Waterman PG and Mole S (eds.): Analysis of Phenolic Plant Metabolites. Blackwell Scientific Publications, Oxford, UK, 1994.

13. Yen GC and Duh PD: Scavenging effect of methanolic extracts of peanut hulls on free-radical and active-oxygen species. J Agr Food Chem 42: 629-632, 1994.

14. Imlay JA, Chin SM and Linn S: Toxic DNA damage by hydrogen peroxide through the Fenton reaction in vivo and in vitro. Science 240: 640-642, 1988.

15. Orrenius S: Apoptosis: molecular mechanisms and implications for human disease. J Intern Med 237: 529-536, 1995.

16. Eguchi R, Toné S, Suzuki A, et al: Possible involvement of caspase- 6 and -7 but not caspase- 3 in the regulation of hypoxiainduced apoptosis in tube-forming endothelial cells. Exp Cell Res 315: 327-335, 2009.

17. Ghobrial IM, Witzig TE and Adjei AA: Targeting apoptosis pathways in cancer therapy. CA Cancer J Clin 55: 178-194, 2005.

18. Martinou JC and Youle RJ: Mitochondria in apoptosis: Bcl-2 family members and mitochondrial dynamics. Dev Cell 21: 92-101, 2011.

19. Youle RJ and Strasser A: The BCL-2 protein family: opposing activities that mediate cell death. Nat Rev Mol Cell Biol 9: 47-59, 2008.

20. Fan TJ, Han LH, Cong RS and Liang J: Caspase family proteases and apoptosis. Acta Biochim Biophys Sin (Shanghai) 37: 719-727, 2005.

21. Besson A, Dowdy SF and Roberts JM: CDK inhibitors: cell cycle regulators and beyond. Dev Cell 14: 159-169, 2008.

22. Levav-Cohen Y, Goldberg Z, Tan KH, Alsheich-Bartok O, Zuckerman V, Haupt S and Haupt Y: The p53-Mdm2 loop: A critical juncture of stress response. Subcell Biochem 85: 161-186, 2014.

23. Shieh SY, Ikeda M, Taya Y and Prives C: DNA damage-induced phosphorylation of p53 alleviates inhibition by MDM2. Cell 91: 325-334, 1997.

24. Xu J, Lian LJ, Wu C, Wang XF, Fu WY and Xu LH: Lead induces oxidative stress, DNA damage and alteration of p53, Bax and Bcl-2 expressions in mice. Food Chem Toxicol 46: 1488-1494, 2008.

25. Sakaguchi K, Herrera JE, Saito S, et al: DNA damage activates p53 through a phosphorylation-acetylation cascade. Genes Dev 12: 2831-2841, 1998

26. Teufel DP, Bycroft M and Fersht AR: Regulation by phosphorylation of the relative affinities of the $\mathrm{N}$-terminal transactivation domains of p53 for p300 domains and Mdm2. Oncogene 28: 2112-2118, 2009.

27. Fang J-Y and Lu Y-Y: Effects of histone acetylation and DNA methylation on p21 ${ }^{\text {WAFI }}$ regulation. World J Gastroenterol 8: 400-405, 2002. 